\title{
Case Report: Gouty Tophus of the Larynx
}

\author{
Chung-Yu Hao', Yih-Jeng Tsai'1,2, Hsing-Mei Wu1 ${ }^{1}$, Chia-Jung Lee ${ }^{1 *}$ \\ ${ }^{1}$ Department of Otolaryngology, Head and Neck Surgery, Shin Kong Wu Ho-Su Memorial Hospital, Taiwan \\ ${ }^{2}$ College of Medicine, Fu Jen Catholic University, Taiwan \\ Email: *gialon12@gmail.com
}

How to cite this paper: Hao, C.-Y., Tsai, Y.-J., Wu, H.-M. and Lee, C.-J. (2021) Case Report: Gouty Tophus of the Larynx. International Journal of Otolaryngology and Head \& Neck Surgery, 10, 43-48.

https://doi.org/10.4236/ijohns.2021.101005

Received: December 27, 2020

Accepted: January 26, 2021

Published: January 29, 2021

Copyright (๑) 2021 by author(s) and Scientific Research Publishing Inc. This work is licensed under the Creative Commons Attribution International License (CC BY 4.0).

http://creativecommons.org/licenses/by/4.0/

\begin{abstract}
Gout is a metabolic disorder that is characterized by a deposition of monosodium urate crystals in the joint or soft tissue. Gout manifestations in head and neck region are rare, and larynx is an infrequently affected location. We recently managed a case of a gouty tophus over the larynx. A 65-year-old male with a long history of gout without medical control. He has suffered from increasing hoarseness for six months. Laryngoscopy revealed a mass lesion over the right vocal process region without vocal paralysis. Laryngo-micro-surgery biopsy was taken, and pathology confirmed laryngeal gouty tophus without evidence of malignancy.
\end{abstract}

\section{Keywords}

Gout, Tophus, Larynx, Purine, Monosodium Urate Crystals

\section{Introduction}

Gout, also known as metabolic arthritis, is a purine metabolic disorder caused by uric acid accumulation in and around joints. Deposited urate crystals accumulate within joints causing inflammation. Gout is more common in men with a peak incidence in the fifth decade. It is characterized by sudden, severe attacks of pain, swelling, redness and tenderness in the joints, especially the first metatarsophalangeal (MTP1) joint. Wrist, ankle and knee joints are also common sites of inflammation. Although the larynx is an infrequently affected location, gouty involvement of the larynx can lead to significant laryngeal symptoms. To our knowledge, few case reports of laryngeal manifestation of gout have been reported and published. We present a case of 65-year-old male suffering from hoarseness for six months. Laryngoscopy revealed a hemispherical mass with a smooth surface over the right vocal process and pathology showed laryngeal gouty tophus. The case is followed by a discussion of the pathophysiology of the disease and a review of the literature. A written consent and approval were ob- 
tained from the patient for the publication of this manuscript.

\section{Case Report}

A 65-year-old male presented with a chief complaint of increasing hoarseness over a period of six months. Associated symptoms including throat pain, odynophagia and globus sensation, but no dysphagia or dyspnea, were noted. Past medical history was significant for hypertension, diabetes, dyslipidemia and a long history of gout without medical control. Tophi had developed in multiple separate anatomic locations such as fingers, hand, elbow, knee, and feet that led to joint deformity and range of motion limitation (Figure 1). Lab data reported a plasma urate concentration of $9.3 \mathrm{mg} / \mathrm{dl}$. Laryngoscopy revealed a hemispherical mass with a smooth surface over the right vocal process region. No vocal fold motion impairment or other specific findings were noted during laryngoscopy and stroboscopy (Figure 2). The patient was brought to the operating room for microlaryngosurgery. A solid hemispherical mass was noted over the right vocal process region, and we performed a tumor biopsy of the mass under microlaryngoscopy. Histopathological examination of the specimen revealed necrotic debris and squamous mucosa with granulation tissue, acute and chronic inflammation, parakeratosis and squamous hyperplasia. Lobules of tophus surrounded by histiocytes were observed, and there was no evidence of malignancy (Figure 3). The patient had an uneventful postoperative course with partial resolution of laryngeal symptoms at two weeks. The patient was referred to the rheumatology service for further consultation. Urate-lowering treatment was initiated under our rheumatologist's suggestion. The patient's plasma urate concentration lowered to $5.8 \mathrm{mg} / \mathrm{dl}$ after six months of medication control. At our otolaryngology follow-up, the laryngeal gouty tophus decreased in size but did not resolve completely. Further follow-up was suggested for monitoring the change of laryngeal gouty tophus.
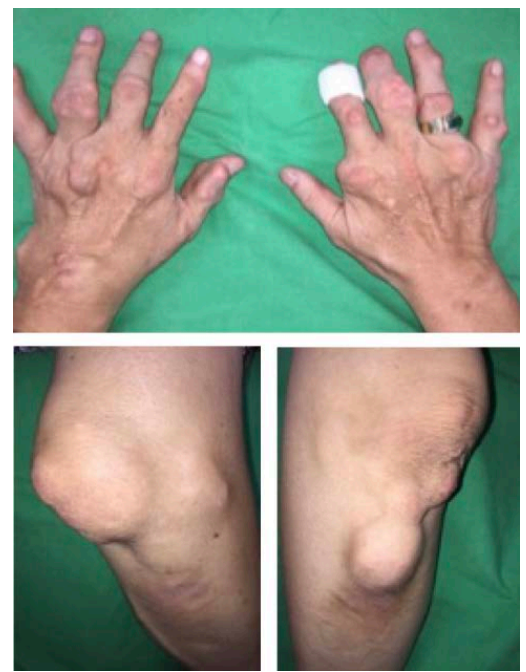

Figure 1. Gouty tophus had developed over the patient's fingers, hands and knees causing joint deformity and range of motion limitation. 


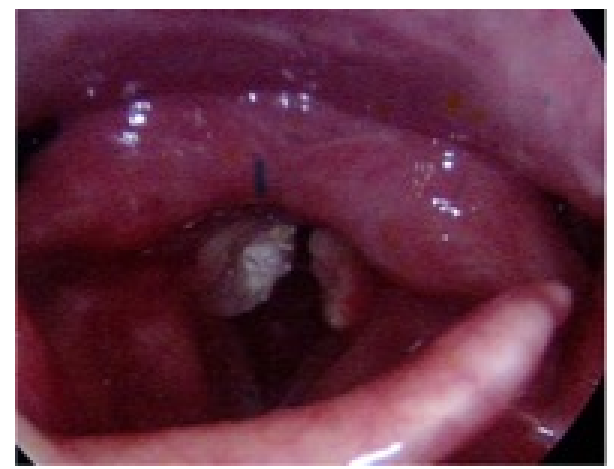

Figure 2. Laryngoscopy revealed a hemispherical tumor over the right vocal process region without vocal palsy.

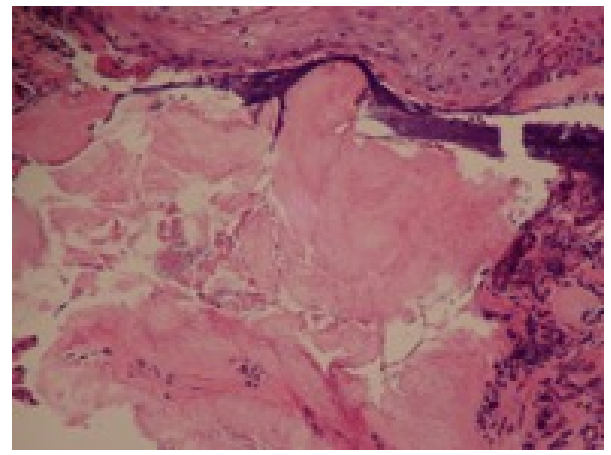

Figure 3. Histopathological examination showed lobules of tophus surrounded by histiocytes, necrotic debris and squamous mucosa with granulation tissue.

\section{Discussion}

Gout is a purine metabolism disorder caused by an increase of urate production, a decrease of uric acid excretion, or a combination of both process [1] [2]. Gouty arthritis develops in only $15 \%$ to $25 \%$ of the patients with hyperuricemia; $95 \%$ of the patients are men with a peak incidence in the fifth decade [2]. The principal determinant of urate deposition in joints is the serum urate level. [2] Hyperuricemia is defined as a serum level above MSU saturation point $(>7.0 \mathrm{mg} / \mathrm{dL})$, at which point the risk of crystallization increases [3] [4] [5] [6]. Gout is characterized by sudden, severe attacks of pain, swelling, redness and tenderness in the joints, especially at the first metatarsophalangeal (MTP1) joint [7]. Wrist, ankle and knee joints are also common sites of inflammation. Although the larynx is an infrequently affected location, gouty involvement of the larynx can lead to significant laryngeal symptoms.

The first description of a gout-associated lesion present within the larynx was made by Garrod in 1863 [8]. Goodman et al. described the first case report with pathologic confirmation in 1976 [8]. Ewart listed the symptoms of gouty laryngitis, including hoarseness, cough, and occasional scant, blood-stained expectoration [8]. Although gout most commonly affects joints at the base of big toe, wrist, ankle and knee area, the larynx is an infrequently affected location. Urate depositions most commonly occur at the synovial fluid of a joint. Patients with 
gouty cricoarytenoid joint involvement usually present with impaired mobility of the vocal fold, and cricoarytenoid fixation can be demonstrated under laryngoscopy [1] [2]. Patients with laryngeal gouty involvement usually have a long-standing history of chronic polyarticular arthritis [8]. Non-specific symptoms such as throat pain, odynophagia, dysphagia, hoarseness, lumping throat, and dyspnea may be encountered [2] [9]. Patients with known gout history with symptoms related to the larynx should be evaluated by an otolaryngologist, and laryngeal gouty involvement should be considered in the differential diagnosis. Malignancy should be ruled out with a biopsy. The diagnosis of laryngeal gouty tophus is based on histopathology [1]. Tophi lesions harbor needle-shaped, negatively birefringent MSU crystals, which is surrounded by soft tissue and inflammatory cells that are microscopically evident [2] [6]-[13]. Extracellular trapping of crystals by neutrophils contribute to typhus formation. A typhus contains three primary zones: a central core of MSU crystals; a surrounding, high density, cellular coronal zone; and an outer fibrovascular zone. Both of the coronal and fibrovascular zones contain many macrophages and plasma cells, fewer mast cells, and scattered $\mathrm{T}$ and B lymphocytes [6] [7] [10] [11] [13].

The central strategy for effective treatment of gout is longterm urate-lowering therapy to a serum urate concentration low enough to achieve MSU crystal dissolution. The 2012 American College of Rheumatology (ACR) guidelines recommend that the presence of gouty tophi is a definite indication for urate-lowering therapy in an individual with gout [7] [14]. The ACR guidelines advise that for most patients with gout, the target serum urate concentration is $<6 \mathrm{mg} / \mathrm{dL}$, but that for those with gouty tophi, a lower target serum urate of $<5 \mathrm{mg} / \mathrm{dL}$ may be required to improve the signs and symptoms of disease. These recommendations are based on data from observational studies demonstrating that the velocity of tophus resolution is inversely related to serum urate concentration and that tophus resolution occurs only at concentrations $<6 \mathrm{mg} / \mathrm{dL}$ [7] [15] [16]. Our patient's initial plasma urate concentration was elevated $(9.3 \mathrm{mg} / \mathrm{dL})$. After six months of urate-lowering medication use, it lowered to $5.8 \mathrm{mg} / \mathrm{dL}$. His laryngeal gouty tophus decreased in size but did not resolve completely. However, his voice and globus sensation improved over time. Further otolaryngology follow up was suggested to evaluate the change of laryngeal gouty tophus.

\section{Conclusion}

Laryngeal gout should be included in the differential diagnosis in patients with unexplained laryngeal symptoms and a known gout history. Biopsy and histopathologic examination of lesions are required for the establishment of a diagnosis. Malignancy should always be excluded. Surgical resection of the tophus lesions must be followed by adequate medical treatment and diet/lifestyle modification to retain a purine metabolic balance. Increased awareness and lower thresholds of suspicion may lead to better clinical recognition and allow earlier diagnosis and treatment of laryngeal gouty tophus. 


\section{Conflicts of Interest}

The authors declare no conflicts of interest regarding the publication of this paper.

\section{References}

[1] Habermann, W., Kiesler, K., Eherer, A., Beham, A. and Friedrich, G. (2001) Laryngeal Manifestation of Gout: A Case Report of a Subglottic Gout Tophus. Auris Nasus Larynx, 28, 265-267. https://doi.org/10.1016/S0385-8146(00)00119-X

[2] Goodman, M., Montgomery, W. and Minette, L. (1976) Pathologic Findings in Gouty Cricoarytenoid Arthritis. Archives of Otolaryngology, 102, 27-29. https://doi.org/10.1001/archotol.1976.00780060073008

[3] Martillo, M.A., Nazzal, L. and Crittenden, D.B. (2014) The Crystallization of Monosodium Urate. Current Rheumatology Reports, 16, 400. https://doi.org/10.1007/s11926-013-0400-9

[4] Lin, K.C., Lin, H.Y. and Chou, P. (2000) The Interaction between Uric Acid Level and Other Risk Factors on the Development of Gout among Asymptomatic Hyperuricemic Men in a Prospective Study. The Journal of Rheumatology, 27, 1501-1505.

[5] Hall, A.P., Barry, P.E., Dawber, T.R. and McNamara, P.M. (1967) Epidemiology of Gout and Hyperuricemia. A Long-Term Population Study. The American Journal of Medicine, 42, 27-37. https://doi.org/10.1016/0002-9343(67)90004-6

[6] Chen, S.L., Chen, J.R. and Yang, S.W. (2019) Painless Gouty Tophus in the Nasal Bridge: A Case Report and Literature Review. Medicine (Baltimore), 98, e14850. https://doi.org/10.1097/MD.0000000000014850

[7] Chhana, A. and Dalbeth, N. (2015) The Gouty Tophus: A Review. Current Rheumatology Reports, 17, 19. https://doi.org/10.1007/s11926-014-0492-X

[8] Guttenplan, M.D., Hendrix, R.A., Townsend, M.J. and Balsara, G. (1991) Laryngeal Manifestations of Gout. Annals of Otology, Rhinology, and Laryngology, 100, 899-902. https://doi.org/10.1177/000348949110001108

[9] Lefkovits, A.M. (1965) Gouty Involvement of the Larynx. Report of a Case and Review of the Literature. Arthritis \& Rheumatology, 8, 1019-1026. https://doi.org/10.1002/art.1780080513

[10] Dalbeth, N., Pool, B., Gamble, G.D., et al. (2010) Cellular Characterization of the Gouty Tophus: A Quantitative Analysis. Arthritis \& Rheumatology, 62, 1549-1556. https://doi.org/10.1002/art.27356

[11] Lee, S.J., Nam, K.I., Jin, H.M., et al. (2011) Bone Destruction by Receptor Activator of Nuclear Factor kappaB Ligand-Expressing T Cells in Chronic Gouty Arthritis. Arthritis Research \& Therapy, 13, R164. https://doi.org/10.1186/ar3483

[12] Liao, P.H. and Chang, K.P. (2016) Nasal Gouty Tophus. Ear, Nose \& Throat Journal, 95, 478-480. https://doi.org/10.1177/014556131609501206

[13] Palmer, D.G., Hogg, N., Denholm, I., Allen, C.A., Highton, J. and Hessian, P.A. (1987) Comparison of Phenotype Expression by Mononuclear Phagocytes within Subcutaneous Gouty Tophi and Rheumatoid Nodules. Rheumatology International, 7, 187-193. https://doi.org/10.1007/BF00541376

[14] Khanna, D., Fitzgerald, J.D., Khanna, P.P., et al. (2012) American College of Rheumatology Guidelines for Management of Gout. Part 1: Systematic Nonpharmacologic and Pharmacologic Therapeutic Approaches to Hyperuricemia. Arthritis Care \& Research (Hoboken), 64, 1431-1446. https://doi.org/10.1002/acr.21772 
[15] Sofka, C.M. (2007) Ultrasonographic Measurement of Tophi as an Outcome Measure for Chronic Gout. Ultrasound Quarterly, 23, 293-294.

https://doi.org/10.1097/01.ruq.0000302192.47413.16

[16] Khanna, D., Khanna, P.P., Fitzgerald, J.D., et al. (2012) American College of Rheumatology Guidelines for Management of Gout. Part 2: Therapy and Antiinflammatory Prophylaxis of Acute Gouty Arthritis. Arthritis Care \& Research (Hoboken), 64, 1447-1461. https://doi.org/10.1002/acr.21773 